\title{
The thioredoxin reductase activity and hypoxia-inducible factor 1 alpha level in anaerobic and aerobic macrophages
}

\author{
Demirpence $\mathrm{O}^{1}$, Tunc $\mathrm{T}^{2}$, Aydin $\mathrm{H}^{1}$, Sumer $\mathrm{Z}^{2}$, Celik $\mathrm{KV}^{1}$, Dogan $\mathrm{HO}^{1}$, Kukul Guven $\mathrm{MF}^{3}$ \\ Cumhuriyet University, Faculty of medicine, Department of Biochemistry, Sivas, Turkey. \\ odemirpence@gmail.com
}

\begin{abstract}
OBJECTIVES: This study was aimed to demonstrate the thioredoxin reductase (TrxR) activities and HypoxiaInducible Factor 1 alpha (HIF-1 $\alpha$ ) levels in macrophage cell line incubated in aerobic and anaerobic settings. BACKGROUND: Pathological situations including inflammatory disorders are associated with the infiltration of phagocyte system cells into damaged tissues. Whenever the environment of tissues converts into hypoxic conditions, phagocytic cells develop an adaptive mechanism in order to fulfill their defense functions.

MATERIALS AND METHODS: The macrophage cells were prepared as two replications both for aerobic and anaerobic media. The E. coli bacteria were inoculated onto the some macrophage culture mediums. TrXR and HIF-1a levels of the samples, obtained from all growth cultures, were measured with the ELISA.

RESULTS: On the 5th and 6th day, there was a continuous increase in the count of bacteria in the aerobic medium, while a continuous decrease in the count of bacteria in the anaerobic medium.

The TrxRand the HIF-1a levels in the groups with anaerobic and aerobic macrophages with or without $\mathrm{E}$. coli bacteria were evaluated. A statistically significant difference was found between these groups in terms of TrxR and HIF-1 $\alpha$ levels $(p<0.05)$.

CONCLUSIONS: Increased TrXR and HIF-1 $\alpha$ levels were thought to have an effect on the adaptation of the macrophages in the anaerobic environment (Tab. 5, Fig. 2, Ref. 23). Text in PDF www.elis.sk. KEY WORDS: macrophage, thioredoxin reductase, hypoxia-inducible factor alpha.
\end{abstract}

\section{Introduction}

Pathological situations including infectious and inflammatory disorders are associated with the infiltration of phagocyte system cells, into damaged tissues (1). Macrophages, whose activity increases in response to injuries or infections are the major component of the mononuclear phagocyte system $(1,2)$. Whenever the environment of tissues converts into hypoxic conditions, phagocytic cells develop adaptive mechanism in order to fulfill their defense functions. Hypoxia regulates macrophage functions in inflammation (3). In case of hypoxia, macrophages may develop more mitogenic, pro-invasive, pro-angiogenic and pro-metastatic phenotypes (4).

HIF-1-mediated mechanisms that have adaptive mechanism for hypoxic conditions, play an important role in macrophage responses to bacterial infections (3). HIF- $1 \alpha$, which is a heterodimeric transcription factor, has an important role in the organism in the reply to low oxygen stress (5). Under hypoxic conditions, for ATP synthesis needed by the living organism, HIF-1 $\alpha$ binds

${ }^{1}$ Cumhuriyet University, Faculty of medicine, Department of Biochemistry, Sivas, Turkey, ${ }^{2}$ Cumhuriyet University, Faculty of medicine, Department of Microbiology, Sivas, Turkey, and ${ }^{3}$ Cumhuriyet University, Faculty of medicine, Department of Emergency, Sivas, Turkey

Address for correspondence: O. Demirpence, MD, Department of Biochemistry, Faculty of Medicine, Cumhuriyet University, Sivas, Turkey. Phone: +90.530.3468916, Fax: +90.530.3462191110 to hypoxia response elements and activates glucose carriers and the transcription of genes that encode the glycolytic enzymes such as hexokinase $(6,7,8)$. In the hypoxic areas of inflamed tissues, HIF-1 $\alpha$ also activates the myeloid cell accumulation into hypoxic area, macrophage-mediated amplification of the inflammatory response, cell proliferation, angiogenesis, transcription of genes helping tissue re-modeling $(4,9)$.

HIF-1 $\alpha$ level can be increased by Thioredoxin (Trx), which is a redox protein $(7,8)$. One of the major antioxidant systems is the thioredoxin redox system consisting of: Trx, TrxR, and NADPH (10). The TrxRs are the members of the flavoprotein family of pyridine nucleotide-disulphide oxidoreductases, reduces oxidized protein substrates in an NADPH-dependent process (11).

TrxRs are selenoprotein enzymes, which play roles in various reduction pathways through reversible oxidation of the cysteine residues at their active site. Production of the TrxR is increased by oxidative stress, hypoxia and viral infections (10). Some studies demonstrated that Trx/TrxRsystem serves as a cofactor in DNA synthesis, inhibits apoptosis, stimulates cell proliferation and angiogenesis, and increases transcription factor activity (7, 12, 13).

In this study, we hypothesized that HIF-1 $\alpha$ and TrxR levels participate in the mechanism of macrophages adaptation to hypoxia. In addition, we observed how phagocytic potency of macrophages changed in aerobic and anaerobic conditions after addition of E.coli bacteria to the cell culture medium. 


\section{Materials and methods}

J774. 1 macrophage cells that were frozen at $-80{ }^{\circ} \mathrm{C}$ were thawed in incubator at $37^{\circ} \mathrm{C}$ and planted on the culture medium. Culture media was refreshed once every 48 hours. Passage was performed when the cells completely covered the flask surface. The cells having an appropriate density were trypsinized. Supernatant was poured after centrifugation and cell count was performed. The cells to be used in the experiments were prepared in DMEM (Dulbecco's Modified Eagle Medium, phenol red stain free) medium to include $5 \times 10^{5} \mathrm{~J} 774.1$ macrophage cells per $\mathrm{mL}$ and suspension was formed by adding 10\% FBS (Fetal Bovine Serum)+ $1 \%$ penicillin streptomycin.

The Cultures including the macrophages were placed in a $\mathrm{CO}_{2}$ incubator, according to the determined line, both under aerobic and anaerobic (in anaerobic jars) conditions.

E. coli bacteria were removed from $-80^{\circ} \mathrm{C}$ and inoculated onto blood agar. This culture was incubated for 24 hours at $37^{\circ} \mathrm{C}$. The passages were done and fresh culture media were prepared one day prior to addition to the DMEM cell culture. Bacteria removed from the fresh cultures were inoculated into the DMEM culture medium used in the cell cultures according to the $0.2 \mathrm{McF}$ arland standards.

At the end of each day of the experiment, suspensions of bacteria were added to the Petri dishes containing the macrophages. They were incubated for 2-3 hours to interact. Afterwards, samples obtained from each Petri dish were inoculated into the blood agar placed in a $\mathrm{CO}_{2}$ incubator at $37^{\circ} \mathrm{C}$, and incubated for 24 hours under both aerobic and anaerobic conditions.

The Macrophages incubated alone in aerobic and anaerobic conditions and also macrophages interacted with E.coli bacteria in both conditions were evaluated. The cells obtained from these cultures were lysed by sonication with a Fisher sonic dismembrator model 300 device (US) and resulted suspensions were examined.

The HIF-1 $\alpha$ levels of the resulted suspensions were examined with ELISA method (Cell-Based ELISA; R\&D Systems, US). The results were expressed as optical density (OD).

TrxR activity levels were examined with ELISA method (Thioredoxin Reductase (TrxR) Assay Kit; Cayman Chemical Company, US). The results were expressed as $\mu \mathrm{mol} / \mathrm{min} / \mathrm{ml}$.

\section{Statistical analysis}

The data analysis was performed using the SPSS for Windows, version 22 (SPSS Inc., Chicago, IL, United States). The normality of distribution was tested using the Kolmogorov-Smirnov test, and parametric or non-parametric tests were used to test data according to normal or non-normal distributions. Data were expressed as the mean \pm standard deviation. The differences between the anaerobic and aerobic groups were investigated by independent-samples $\mathrm{T}$ test, One-way ANOVA and Tuckey test. The repeated measures were investigated by analysis of variance using the general linear models approach. The value of $\mathrm{p}<0.05$ was considered statistically significant.

\section{Results}

After adding E.Coli to aerobic and anaerobic cultivation media of macrophages, no bacterial growth was observed within the following 48 hours. On the third day, no bacteria grew in the aerobic medium while plenty of bacteria $\left(1 \times 10^{5} \mathrm{cfu} / \mathrm{mL}\right)$ grew in the anaerobic medium. On the fourth day, $6 \times 10^{2} \mathrm{cfu} / \mathrm{mL}$ bacteria grew in the aerobic medium and plenty of bacteria $\left(1 \times 10^{5} \mathrm{cfu} / \mathrm{mL}\right)$ grew in the anaerobic medium. On the 5 th day, $2 \times 10^{3} \mathrm{cfu} / \mathrm{mLb}$ bacteria

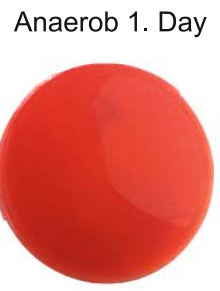

Anaerob 2. Day
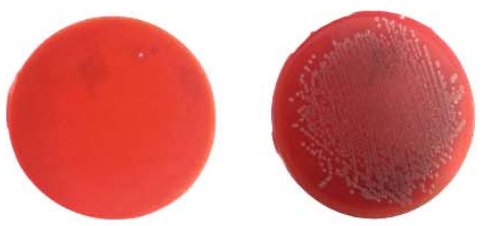

Anaerob 4. Day

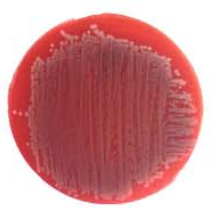

Anaerob 6. Day
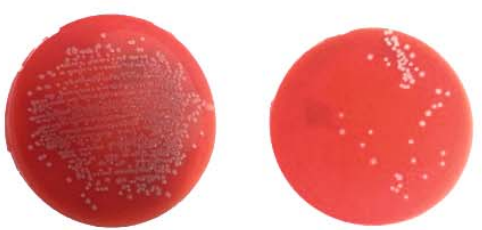

Fig. 1. Bacterial growth, after adding E. coli to anaerobic cultivation media.
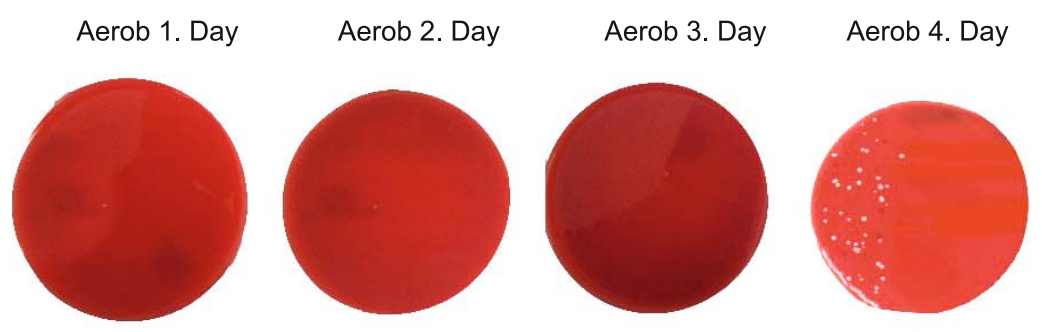

Aerob 5. Day
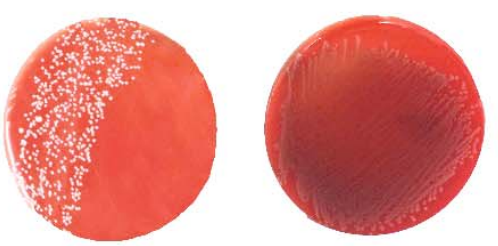

Fig. 2. Bacterial growth, after adding E. coli to aerobic cultivation media. 
Tab. 1. HIF-1 $\alpha^{*}$ and TrxR activity** levels in the anaerobic and aerobic medium with or without E. coli bacteria.

\begin{tabular}{lcccc}
\hline & Culture medium & $\mathrm{n}$ & Mean & $\mathrm{p}$ \\
\hline \multirow{4}{*}{ Hif 1 alfa } & Aerobic (-Ecoli) & 6 & $0.042 \pm 0.002$ & $\mathrm{~F}=6.07$ \\
& Aerobic (+Ecoli) & 6 & $0.043 \pm 0.003$ & $\mathrm{P}<0.005$ \\
& Anerobic (-Ecoli) & 6 & $0.085 \pm 0.036$ & \\
& Anerobic (+Ecoli) & 6 & $0.094 \pm 0.04$ & \\
\multirow{4}{*}{ Trx R } & Aerobic (-Ecoli) & 6 & $0.281 \pm 0.001$ & \\
& Aerobic (+Ecoli) & 6 & $0.282 \pm 0.001$ & $\mathrm{~F}=10.03$ \\
& Anerobic (-Ecoli) & 6 & $0.289 \pm 0.005$ & $\mathrm{p}<0.005$ \\
& Anerobic (+Ecoli) & 6 & $0.293 \pm 0.007$ & \\
\hline
\end{tabular}

Values of $\mathrm{P}<0.05$ were considered significant.

$*$ Data are expressed as mean \pm std.deviation, OD.

** Data are expressed as mean \pm std.deviation, $\mu \mathrm{mol} / \mathrm{min} / \mathrm{ml}$

Tab. 2. HIF 1 alfa levels* in aerobic medium with and without E. coli bacteria.

\begin{tabular}{lcccc}
\hline & With E. coli & $\mathrm{p}$ & Without E. coli & $\mathrm{p}$ \\
\hline $1^{\text {st }}$ day & $0.042 \pm 0.002$ & & $0.039 \pm 0.002$ & \\
$2^{\text {nd }}$ day & $0.039 \pm 0.003$ & & $0.04 \pm 0.003$ & \\
$3^{\text {rd }}$ day & $0.039 \pm 0.003$ & $\mathrm{~F}=1.113$ & $0.039 \pm 0.003$ & $\mathrm{~F}=0.44$ \\
$4^{\text {th }}$ day & $0.044 \pm 0.009$ & $\mathrm{p}>0.05$ & $0.044 \pm 0.009$ & $\mathrm{p}>0.05$ \\
$5^{\text {th }}$ day & $0.045 \pm 0.003$ & & $0.044 \pm 0.009$ & \\
$6^{\text {th }}$ day & $0.046 \pm 0.01$ & & $0.044 \pm 0.007$ & \\
\hline
\end{tabular}

Values of $\mathrm{P}<0.05$ were considered significant.

*Data are expressed as mean \pm std.deviation, OD.

Tab. 3. HIF 1 alfa levels* in anerobic medium with and without $\mathrm{E}$. coli bacteria.

\begin{tabular}{lcccc}
\hline & With E. coli & $\mathrm{p}$ & Without E. coli & $\mathrm{p}$ \\
\hline $1^{\text {st }}$ day & $0.047 \pm 0.002$ & & $0.045 \pm 0.003$ & \\
$2^{\text {nd }}$ day & $0.063 \pm 0.001$ & & $0.062 \pm 0.002$ & \\
$3^{\text {rd }}$ day & $0.077 \pm 0.002$ & $\mathrm{~F}=976.3$ & $0.066 \pm 0.003$ & $\mathrm{~F}=430$ \\
$4^{\text {th }}$ day & $0.094 \pm 0.001$ & $\mathrm{p}<0.001$ & $0.081 \pm 0.006$ & $\mathrm{p}<0.001$ \\
$5^{\text {th }}$ day & $0.129 \pm 0.002$ & & $0.114 \pm 0.003$ & \\
$6^{\text {th }}$ day & $0.155 \pm 0.005$ & & $0.142 \pm 0.002$ & \\
\hline
\end{tabular}

Values of $\mathrm{P}<0.05$ were considered significant.

$*$ Data are expressed as mean \pm std.deviation, OD.

grew in the aerobic medium, while approximately $4 \times 10^{3} \mathrm{cfu} / \mathrm{mL}-$ bacteria grew in the anaerobic medium. On the 6th day, plenty of bacteria $\left(1 \times 10^{5} \mathrm{cfu} / \mathrm{mL}\right)$ grew in the aerobic medium, while $6 \mathrm{x}$ $10^{2} \mathrm{cfu} / \mathrm{mLbacteria}$ grew in the anaerobic medium (Figs 1 and 2).

The HIF-1 $\alpha$ levels of the groups with anaerobic and aerobic macrophages medium with or without E. coli bacteria were evaluated. A statistically significant difference was found between these groups in terms of HIF-1 $\alpha$ levels $(\mathrm{F}=6.07, \mathrm{p}<0.005)$ (Tab.1).

The TrxR activity levels of the groups with anaerobic and aerobic macrophages medium with or without E. coli bacteria were evaluated. A statistically significant difference was found between these groups in terms of TrxR activity levels $(F=10.03$, $\mathrm{p}<0.005)$ (Tab. I).

The inter-day changes in HIF- $1 \alpha$ levels of aerobic macrophages with and without E.coli bacteria was not found statistically significant $(\mathrm{F}=1.113, \mathrm{p}>0.05 ; \mathrm{F}=0.44, \mathrm{p}>0.05$ respectively) (Tab. 2).

The inter-day changes in HIF- $1 \alpha$ levels of anaerobic macrophages with and without $\mathrm{E}$. coli bacteria was found statistically significant $(\mathrm{F}=976.3, \mathrm{p}<0.001 ; \mathrm{F}=429, \mathrm{p}<0.001$ respectively)(Tab. 3).
Tab. 4. TrxR activity levels** in aerobic medium with and without E. coli bacteria.

\begin{tabular}{lcccc}
\hline & With E. coli & $\mathrm{p}$ & Without E. coli & $\mathrm{p}$ \\
\hline $1^{\text {st }}$ day & $0.281 \pm 0.001$ & & $0.281 \pm 0.001$ & \\
$2^{\text {nd }}$ day & $0.282 \pm 0.002$ & & $0.28 \pm 0.001$ & \\
$3^{\text {rd }}$ day & $0.281 \pm 0.002$ & $\mathrm{~F}=0.247$ & $0.281 \pm 0.001$ & $\mathrm{~F}=0.627$ \\
$4^{\text {th }}$ day & $0.282 \pm 0.001$ & $\mathrm{p}>0.05$ & $0.281 \pm 0.002$ & $\mathrm{p}>0.05$ \\
$5^{\text {th }}$ day & $0.281 \pm 0.001$ & & $0.282 \pm 0.002$ & \\
$6^{\text {th }}$ day & $0.282 \pm 0.002$ & & $0.282 \pm 0.001$ & \\
\hline & & \\
Values of $\mathrm{p}<0.05$ were considered significant. \\
* Data are expressed as the mean \pm std.deviation, $\mu \mathrm{mol} / \mathrm{min} / \mathrm{ml}$. &
\end{tabular}

Tab. 5. TrxR activity** levels in anerobic medium with and without E. coli bacteria.

\begin{tabular}{lcccc}
\hline & With E. coli & $\mathrm{p}$ & Without E. coli & $\mathrm{p}$ \\
\hline $1^{\text {st }}$ day & $0.281 \pm 0.001$ & & $0.282 \pm 0.001$ & \\
$2^{\text {nd }}$ day & $0.288 \pm 0.001$ & & $0.286 \pm 0.002$ & \\
$3^{\text {rd }}$ day & $0.292 \pm 0.002$ & $\mathrm{~F}=44.88$ & $0.288 \pm 0.001$ & $\mathrm{~F}=232.11$ \\
$4^{\text {th }}$ day & $0.295 \pm 0.002$ & $\mathrm{p}<0.001$ & $0.290 \pm 0.002$ & $\mathrm{p}<0.005$ \\
$5^{\text {th }}$ day & $0.299 \pm 0.00$ & & $0.295 \pm 0.002$ & \\
$6^{\text {th }}$ day & $0.302 \pm 0.002$ & & $0.294 \pm 0.001$ & \\
\hline
\end{tabular}

Values of $\mathrm{p}<0.05$ were considered significant.

** Data are expressed as the mean \pm std.deviation, $\mu \mathrm{mol} / \mathrm{min} / \mathrm{ml}$.

The inter-day changes in TrxR activity levels of aerobic macrophages with and without $\mathrm{E}$. coli bacteria was not found statistically significant $(\mathrm{F}=0.247, \mathrm{p}>0.05 ; \mathrm{F}=0.627, \mathrm{p}>0.05$ respectively) (Tab. 4).

The inter-day changes in TrxR activity levels of anaerobic macrophages with and without E. coli bacteria was found statistically significant $(\mathrm{F}=44.88, \mathrm{p}<0.001 ; \mathrm{F}=232.11, \mathrm{p}<0.005$ respectively) (Tab. 5).

\section{Discussion}

In the recent study, it was seen that the levels of HIF-1 $\alpha$ and TrxR, which play an important role in the oxygen homeostasis of cells, increases significantly in the macrophages in the anaerobic medium than in those in the aerobic medium. As it is seen in Figures 1 and 2, after adding E. coli bacteria into the aerobic and anaerobic culture media of macrophages, no bacteria grew within the first 2 days. From this observation, we concluded that regardless of the presence of oxygen in the medium, the phagocytic abilities of macrophages were not affected for the first two days. On the $3 \mathrm{rd}$ and 4 th days, there was growth in the anaerobic medium, while there was no growth on3rd day and minimal growth on 4th day in the aerobic medium. From this observation, we concluded that the phagocytic ability diminishes in the anaerobic medium on the $3 \mathrm{rd}$ and 4 th days. On the 5 th and 6th days, there was a continuous increase in count of bacteria in the aerobic medium, while a continuous decrease in count of bacteria in the anaerobic medium, suggesting that the phagocytic power started to increase in the anaerobic medium on the 5 th day.

The TrxR activities and HIF- $1 \alpha$ levels in the groups with anaerobic and aerobic macrophages medium with or without E. coli bacteria were evaluated. A statistically significant difference 
was found between these groups in terms of TrxR activities and HIF-1 $\alpha$ levels. In our study, we determined a continuous increase from 1st day to 6th day in the TrxR activities and HIF-1 $\alpha$ levels of the macrophages prepared with E. coli and without E. coli in the anaerobic medium as compared to those in the aerobic medium (Tabs $1-4)$. The increase in the phagocytic power in the anaerobic medium starting from 5th day suggested that it could be caused by the adaptation to anaerobic medium of the macrophages and that the increased levels of HIF-1 $\alpha$ and TrxR might play a role in this adaptation.

The hypoxia develops because of increasing oxygen consumption in the tissues, where bacteria proliferate. In this hypoxic medium that develops within the bacterial infected tissues, the macrophages should maintain their phagocytic characteristics, thus develop adaptation to life. When a macrophage accumulation occurs in the infected, damaged tissues, by means of HIF 1 and 2 increasing in response to the hypoxy in the environment, transcription factors upregulate and gene expressions change. HIF 1 and 2 consists of alpha subunit and structural beta subunit that could be induced by an apparent hypoxia. In an adequate oxygen pressure, alpha subunits degrade in the cytoplasm, whereas they don't degrade in case of hypoxia, they bind to beta subunit in nucleus and cause expression of hypoxia-induced genes (3). In the study where a new pharmacological substance increasing HIF-1 activity was found and used in vitro, it was stated that HIF-1 activates phagocytosis in the response to bacterial pathogens increasing the immunity response of phagocytes (9). In their study, Peyssonnaux et al have exposed WT macrophages to pharmacological substances inducing HIF- $1 \alpha$ and have observed intracellular killing of group A Streptococcus bacteria by WT macrophages with induction by these agents. In that study bactericidal activity has diminished in the HIF- $1 \alpha$ deficient mice and the restriction of infection's spread was considered as poor. In hypoxic micro-environments, HIF-1 $\alpha$ does not only coordinate the change occurring in the glycoltic metabolism, but also the congenital immune response for bacterial killing. HIF- $1 \alpha$ regulates the production of key immune effector molecules, whose release is stimulated during bacterial infection such as granule proteases, antimicrobial peptides, nitric oxide and TNF- $\alpha$ (14).

HIF-1 $\alpha$ also can regulate anaerobic metabolism. HIF- $1 \alpha$ helps to regulate the oxygen homeostasis by inducing glycolysis, regulating glucose uptake, erythropoiesis and angiogenesis $(5,15)$. Cell level adaptation to hypoxia and altered glucose metabolism is a situation that can also be observed in the cancer cells. HIF-1 $\alpha$ controls angiogenesis and metabolism in the cancer cells, upregulates hypoxia-induced genes such as vascular endothelial growth factor (VEGF) and promotes tumor cell survival under hypoxic conditions. In the immunohistochemical study on gastric adenocarcinoma, increased HIF-1 $\alpha$ level has shown a significant correlation with p53 and VEGF protein expression (16).

It has been reported in a number of studies that the stabilization of HIF- $1 \alpha$ and the activation of related genes can be regulated by Trx molecule $(17,18)$. In the study conducted under normoxic and hypoxic conditions on the cell cultures of human MCF-7 breast cancer, human HT-29 colon cancer and mouse WEHI7.2 lym- phoma cell lines, when HIF-1 $\alpha$ protein levels, VEGF production and tumor angiogenesis in the cell cultures transfected with Trx were compared with wild-type or empty vector-transfected cells, an increase in the HIF- $1 \alpha$ protein level was observed. HIF- $1 \alpha$ level or activity can be controlled by Trx redox system activity. On the other hand, it has not been clarified how this redox activity affects the HIF-1 $\alpha$ signalization paths, regulates hypoxic response and by means of which mechanisms affects HIF-1 $\alpha$ function (19). It has been demonstrated that overproduction of the TrxR significantly increases HIF-1 $\alpha$ both under normoxic and hypoxic conditions (7). In this study, the TrxR activity level, which is a component of the Trx redox activity, was evaluated and it was a restriction of our study that we couldn't evaluate the Trx level.

Several redox-based systems might play regulatory roles in macrophage activation. On the other hand, it has not been clarified, how they affect specific macrophage functions $(20,21)$. The Trx/TrxR redox system have important biochemical roles such as, in cytoprotection, cell proliferation, angiogenesis and regulation of cell death (22).

Isakovet al. in their study have reported that as an adaptive immune response to infectious agents, the macrophage activity is regulated by means of cellular signals. In this study, it was stated that, by inhibition of the TrxR by means of auranofin in macrophage cell cultures, the activation of NLRP3 / IL-1 $\beta$ signal pathway is suppressed causing anti-inflammatory impacts (23). In this study, we evaluated the TrxR activities found as increased in the anaerobic medium as compared to aerobic medium. In addition, this TrxR activities found an increase after adding E. coli to these mediums. We suggest that by increase of macrophage TrxR level with addition of bacteria into the cell culture, the inflammation is attempted to be limited in the anaerobic medium.

After a literature scan, it was seen that there were few studies that deals with the evaluation of the levels of HIF-1 $\alpha$ and TrxR activity in macrophage cell cultures. Consequently, we suggest that, thanks to their ability of increasing phagocytic cell activity, level of HIF- $1 \alpha$ and TrxR activity increasing as the result of hypoxia developing in the bacterial infected tissue can be a new therapeutic target for increasing host defense.

\section{References}

1. Saadi S, Wrenshall LE, Platt JL. Regional manifestations and control of the immune system. Faseb J 2002; 16 (8): 849-856.

2. Zinkernagel SA, Johnson RS, Nizet V. Hypoxia inducible factor (HIF) function in innate immunity and infection. J Mol Med 2007; 85 (12): 1339-1346.

3. Murdoch C, Muthana M, Lewis CE. Hypoxia Regulates Macrophage Functions in Inflammation Immunol 2005; 175: 6257-6263.

4. Riboldi E, Porta C, Morlacchi S, Viola A, Mantovani A, Sica A. Hypoxia-mediated regulation of macrophage functions in pathophysiology. Int Immunol2013; 25 (2): 67-75.

5. Ziello JE, Jovin IS, Huang Y. Hypoxia-Inducible Facotr (HIF)-1 regulatory pathway and its potential for therapeutic intervention in malignancy and ischemia. Yale J Biol Med 2007; 80 (2): 51-60. 


\section{$226-230$}

6. Semenza GL. Hypoxia-Inducible Factors in Physiology and Medicine. Cell 2012; 148 (3): 399-408.

7. Biaglow JE, Miller RA. The Thioredoxin Reductase/Thioredoxin System.Cancer Biol Ther2005; 4 (1): 6-13.

8. Semenza GL. Hypoxia, Clonal Selection, and the Role of HIF-1 in Tumor Progression. Crit Rev Biochem Mol Biol2000; 35 (2): 71-103.

9. Okumura CY, Hollands A, Tran DN et al. A New Pharmacological Agent (AKB-4924) Stabilizes Hypoxia Inducible Factor (HIF) and Increases Skin Innate Defenses Against Bacterial Infection. J Mol Med (Berl) 2012; 90 (9): 1079-1089.

10. Hashemy IS. The Human Thioredoxin System: Modifications and Clinical Applications.Iran J Basic Med Sci 2011; 14 (3): 191-204.

11. Mustacich D, Powis G. Thioredoxin reductase. Biochem J 2000; 346: Pt 1: 1-8.

12. Powis G, Montfort WR. Properties and biological activities of thioredoxins. Annu Rev Pharmacol Toxicol 2001; 41: 261-295.

13. Gromer S, Urig S, Becker $\mathbf{K}$. The thioredoxin system--from science to clinic. Med Res Rev 2004; 24: 40-89.

14. Peyssonnaux C, Datta V, Cramer T et al. HIF-1 $\alpha$ expression regulates the bactericidal capacity of phagocytes. J Clin Invest 2005; 115 : 1806-1815.

15. Carmeliet P, Dor Y, Herbert MJ et al. Role of HIF-1 $\alpha$ in hypoxia-mediated apoptosis, cell proliferation and tumour angiogenesis. Nature 1998; 394: 485-490.

16. Urano N, Fujiwara Y, Doki Y et al. Overexpression of hypoxiainducible factor-1 alpha in gastric adenocarcinoma Gastric Cancer 2006; 9: 44-49.
17. Welsh SJ, Bellamy TW, Briehl MM, Powis G. The Redox Protein Thioredoxin-1 (Trx-1) Increases Hypoxia-inducible Factor $1 \alpha$ Protein Expression: Trx-1 Overexpression Results in Increased VascularEndothelial Growth Factor Production and EnhancedTumor Angiogenesis. Cancer Research 2002; 62: 5089-5095.

18. Zhou J, Damdimopoulos AE, Spyrou G, Brüne B.Thioredoxin 1 and Thioredoxin 2Have Opposed RegulatoryFunctions on Hypoxia-inducible Factor-1 $\alpha$ *J Biol Chem 2007; 282 (10): 7482-7490.

19. Suarez NS, Carlson BA, Tobe R, Yoo MH, Tsuji PA, Gladyshev VN, Hatfield DL. Regulation of HIF-1 $\alpha$ Activity by Overexpression of Thioredoxin is Independent of Thioredoxin Reductase Status. Mol Cells 2013; 36: 151-157.

20. Wink DA, Hines HB, Cheng RY et al. Nitric oxide and redox mechanisms in the immune response. J Leukoc Biol 2011; 89: 873-891.

21. Lugrin J, Rosenblatt-Velin N, Parapanov R, Liaudet $\mathbf{L}$. The role of oxidative stress during inflammatory processes. Biol Chem 2014; 395 : 203-230.

22. Söderberg A, Sahaf B, Rosén A. Thioredoxinreductase, aredox-activeselenoprotein, issecretedbynormalandneoplasticcells: presenceinhuman. plasma. Cancer Res.2000; 60 (8): 2281-2289.

23. Isakov E, Weisman-Shomer $\mathbf{P}$, Benhar M. Suppression of the proinflammatory NLRP3/interleukin-1 $\beta$ pathway in macrophages by the thioredoxin reductaseinhibitor auranofin. Biochim Biophys Acta 2014; 1840 (10): 3153-3161.

Received July 14, 2015. Accepted August 11, 2015. 